nucioso- pero en el que, en cambio, la presencia de San Jerónimo es similar al ejemplar madrileño. Los nimbos de los niños, presentes en la versión Bernstein, casi no existen en la alicantina y han desaparecido en la recientemente aparecida, en la que también se hecha de menos la mano de Jesús sobre la parte posterior de la cabeza del evangelista niño, sustituida por una incipiente insinuación de un nimbo, tal vez debido a una restauración. La limpieza del cuadro recientemente aparecido en el comercio madrileño ha recuperado calidades en el sutil velo que cubría excesivamente el cuerpo del Niño Jesús (fig. 6), dejándolo al descubierto como en las otras versiones. Los modelos de la Virgen y el Niño nos evocan los de la Sagrada Familia de Juanes (fig. 7), de la colección León en Tortosa (Tarragona), mostrando ambas versiones una calidad algo menos suave que en las otras versiones, debido tal vez a la reciente limpieza y restauración de la versión localizada en el comercio madrileño.

El éxito del tema es evidente y no podemos sustraernos a la tentación de exponer la reinterpretación que de él hizo Juanes, en los Desposorios místicos con el Beato Agnesio (fig. 8), en que se suman, a la iconografía de los santos Juanitos, dos «santos inocentes» ${ }^{7}$, aportando interés iconográfico al tema pasionario.

IsABel Mateo Gómez Dpto. Arte. CSIC

\title{
ESTEBAN JAMETE EN BURGOS
}

En el mes de noviembre de 1535 Esteban Jamete, después de ganar el jubileo en Santiago de Compostela y estar unos días en Medina de Rioseco, se encaminó hacia Burgos. La presencia en esta ciudad del escultor Felipe Vigarny, compatriota suyo que gozaba de gran prestigio en Castilla y del que con toda seguridad había tenido noticia, fue probablemente la razón de su viaje.

Para Jamete su paso por esta ciudad, en la que con tanta fuerza había arraigado el arte flamenco y en la que con cierta lentitud se había adoptado el nuevo estilo que venia de Italia, fue sumamente enriquecedor, pues además de trabajar con Vigarny, uno de los introductores del Renacimiento en Burgos(aunque en sus primeros trabajos todavía se mostró muy apegado a formulas medievales), también pudo ver en la catedral burgalesa algunas de las obras más representativas del arte refinado y clásico de Diego de Siloe, cuya belleza, un artista como Jamete sin duda supo apreciar.

Al poco tiempo de llegar a Burgos, Jamete entró en el taller de Vigarny y durante los tres meses que duró su estancia en esta ciudad, según nos informa el propio artista ${ }^{1}$, estuvo en casa de mase Felipo a su oficio de entallador labrando de madera donde trabajo en fazer el modelo de las sillas de Toledo de la iglesia mayor. La labor realizada por Jamete debió de gustar a Vigarny, como lo demuestra el hecho de que cuando se procedió a ejecutar esta sillería, fue uno de los artífices que intervino en ella.

\footnotetext{
${ }^{7}$ Considerada por Tormo de la última etapa del pintor y por F. Benito Domenech entre 1553-1558. Este autor en Joan de Joanes. Las bodas místicas del venerable Agnesio. Valencia, Museo de Sant Pius V. 1996 y Exposición Joan de Joanes. Madrid-Valencia, 1979-1980, recoge la datación del cuadro por varios autores.

' Domínguez Ortiz, Proceso inquisitorial contra el escultor Esteban Jamete, Madrid, 1933, pp.24,25.
}

$A E A, \mathrm{LXXV}, 2002,297$, pp. 51 a 88 


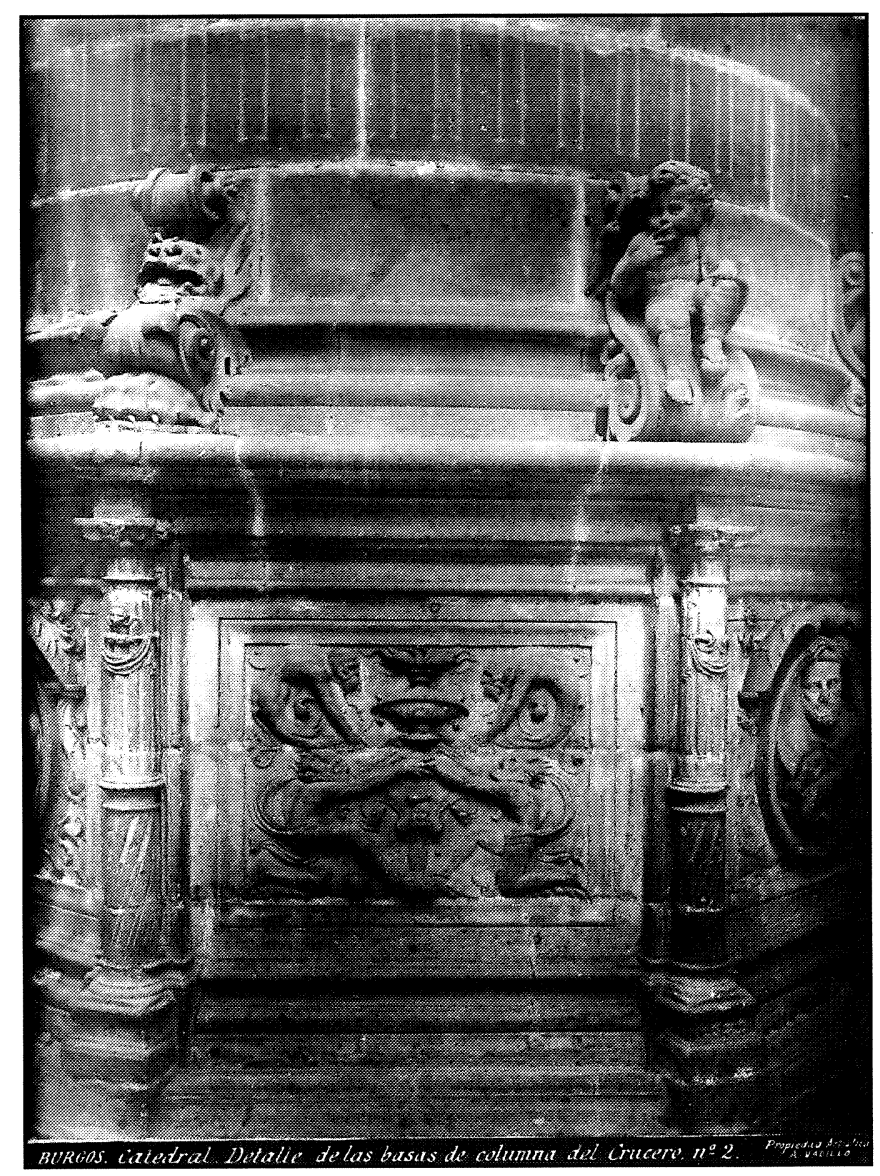

Fig. 1. Esteban Jamete. Detalle de las basas de columna del crucero. Burgos. Catedral.

En febrero de 1536 Jamete abandonó Burgos y se fue a trabajar a Valladolid, marchando más tarde a León. Apenas habían transcurrido unos meses, concretamente en agosto de este mismo año, Jamete volvió a Burgos y como el mismo dice estuvo al pie de tres meses e estuvo en la carçel publica mes e medio e trabajo en la yglesia mayor de la dicha çibdad ${ }^{2}$.

Acerca del motivo por el cual Jamete fue hecho preso nada se dice, aunque no es muy aventurado pensar que su especial talante y sus ideas no muy ortodoxas tendrían algo que ver con su encarcelamiento.

En cuanto a su trabajo en la catedral, Jamete tuvo la oportunidad de dejarnos una buena muestra de su arte en los pilares del crucero, que en esa fecha se estaban reforzando y adornó sus basamentos con bustos, grutescos y empleó ciertos elementos - como son los colgantes que atan las columnas- que desde un principio formaron parte de su repertorio ornamental. Siendo ésta una de las primeras obras que realizó al llegar a nuestro país demuestra la formación tan completa que Jamete traía de su oficio y no es de extrañar el agrado de Vigarny al observar el cuidado y perfección con los que están labrados los medallones, donde una graduación plástica en los volúmenes recorre desde los más delicados bajorrelieves al más expresivo resalte de las figuras (fig. 1).

Cuando Jamete llegó por primera vez a Burgos, el cimborrio, que a mediados del siglo xv había levantado Juan de Colonia, amenazaba ruina y con el fin de evitar su hundimiento, se

\footnotetext{
${ }^{2}$ Domínguez Ortiz, op.cit., p.25.
}

$A E A, \mathrm{LXXV}, 2002,297$, pp. 51 a 88 
había decidido aforrar los pilares que se habían resentido pues no estaban pensados para soportar tan pesada carga. De ahí que, en el capitulo celebrado el 9 de marzo de 1535, el señor abbad de Gamonal obrero de la fabrica leyo en el dicho capitulo un parescer de los maestros canteros acerca de cierto aforro que dize se podria hazer en los pilares del crucero para firmeça del cimborio $^{3}$. Hay que suponer que la obra se puso pronto en marcha, y un año después, el 24 de abril de 1536, los canónigos reunidos en capítulo se ocuparon de nuevo de este problema y platicaron sobre el aforro de los pilares del cruçero y mandaron quel obrero de la fabrica de por sisa la obra del aforro de los pilares ${ }^{4}$. En 1537 se habla ya de los pilares nuevos ${ }^{5}$.

Las obras que se llevaron a cabo para consolidar los pilares, no impidieron que lamentablemente en 1539 el cimborrio se hundiera. Años más tarde, Juan de Vallejo se encargó de levantar la magnífica fábrica que hoy podemos admirar y que se apoya sobre aquellos pilares que Jamete había decorado.

M. ${ }^{a}$ LUZ ROKISKI LÁZARO

Universidad Politécnica de Madrid

\section{SOBRE TRES PAISAJES DE ALTA MONTAÑA DE HAES}

La pretensión de estas breves líneas es la de abordar someramente el asunto de los paisajes de alta montaña de Carlos de Haes, a través de la problemática que nos suscitan dos obras suyas de este tipo (conservadas en el Museo del Prado y en el Museo de Arte Moderno de Barcelona) con respecto a la conexión existente entre ellas y a sus fechas de ejecución y asuntos; así como, en relación con éstas, el estudio de otro paisaje suyo de alta montaña, aparecido en el comercio de Madrid, de problemática similar, no sólo para su catalogación, sino también para su posible datación e identificación temática.

En primer lugar, el asunto de los tres cuadros, que representan paisajes de alta montaña, nos permitiría situar, en líneas generales, sus posibles fechas de realización en un determinado período de la vida y producción pictórica de Haes, quien comenzaría a entrar en contacto con dichos asuntos en 1872, cuando fue a veranear y a pintar a Santander y Vizcaya, descubriendo entonces los paisajes del norte de España, por los que sintió especial inclinación, al ser más acordes con la climatología del norte de Europa a que estaba acostumbrado ', tanto por su formación en Bélgica como por su temperamento. Luego, en 1874, viaja con sus discípulos Aureliano de Beruete y José Entrala a Asturias, entrando ya abiertamente en su temática los paisajes de alta montaña, quizá por sugerencia de Beruete (que ya se relacionaba entonces con el Colegio Internacional y con Giner de los Ríos), siendo con ocasión de este descubrimiento de los Picos de Europa por parte de Haes, cuando, a decir de Pena, «se introdujo de lleno la alta montaña en la iconografía del arte del paisaje español» ${ }^{2}$, lo que es cierto, aunque no debemos

\footnotetext{
${ }^{3}$ Archivo Catedral de Burgos, Actas Capitulares, 1535, fol.189.

${ }^{4}$ Archivo Catedral de Burgos, Actas Capitulares, 1536, fol.296.

${ }^{5}$ En el libro de fábrica hemos encontrado la siguiente noticia: Ymagenes para los pilares nuevos. Recibensele en quenta veinte e siete mill y trezientos y quarenta maravedies que dio y pago a Juan de Villarreal ymaginario por los quatro evangelistas y quatro doctores para los pilares nuevos y una filatera para la capilla de Santiago.(Archivo Catedral de Burgos, Libro de fábrica, 1537, fol. 73).

' Pena, M.C., El paisaje español del XIX: del naturalismo al impresionismo, Universidad Complutense, Madrid, 1982, p. 195.

${ }^{2}$ Ibidem, p. 198.
}

AEA, LXXV, 2002, 297, pp. 51 a 88 